\title{
Parsons, Luhmann and the Theorem of Double Contingency
}

\author{
RAF VANDERSTRAETEN University of Bielefeld
}

\begin{abstract}
This article analyzes the ego/alter ego constellation of social interaction. Every social interaction constitutes a situation with double contingency, which is recognized as such by both sides: both know that both know that one could also act differently. The circularity of the relationship brings about indeterminacy; self-commitment would presuppose that others commit themselves and vice versa. How is this infinity problem solved? How can we account for the possibility of social interaction, and social order? Both Talcott Parsons and Niklas Luhmann have devoted considerable attention to the theorem of double contingency. Here, I analyze their theoretical formulations on this topic.
\end{abstract}

KEYWORDS double contingency, expectations, social interaction, social systems theory, time

Niklas Luhmann (1927-98) had a paradoxical relation with the classical tradition in sociology. On the one hand, he never got tired of criticizing and taunting contemporary sociology's fascination for its founding fathers. In the preface to Soziale Systeme (1984), for example, he bluntly asserts that sociology is stuck in a theory crisis. The discipline offers old bottles into which the data of empirical research are poured. 'To a great extent, those interested in theory return to the classical authors. . . . The task becomes one of dissecting, criticizing, and recombining already-existing texts. What one does not trust oneself to do is assumed to be already at hand' (1995a: xlv). Here, as in other places, Luhmann depicts explorations in the writings of key sociological thinkers as a poor substitute for original theoretical research. The discipline would be better off without 'reliance on illustrious names and specialization in them' (1995a: xlvi). The dissection of each bit of the classical authors hardly contributes to the development of sociological theory. In fact, it leads away from any concern with 
the distinctive characteristics of sociology as a scientific discipline. 'If one dismembers them in this way, however, can one manage without them?' (1995a: xlvi). The cynical tone of this rhetorical question seems to imply that new theoretical projects should not be guided by the writings of the classical authors.

For the development of his own theory of social systems, Luhmann explored a number of other research contexts. His work especially draws on writings in philosophy, general systems theory and cybernetics. In this sense, his writings indeed diverge from the sociological tradition. On the other hand, however, Luhmann typically identified himself as a 'sociologist', and presented his work as 'sociology'. He also justified his excursions outside the discipline in this way: "[T]he advances in abstraction and the new conceptual formations that already exist or are emerging in interdisciplinary contexts should be made usable in sociological research' (1995a: 11). Moreover, Luhmann even published his own painstaking analyses of the writings of founding fathers of the discipline, such as Max Weber and Émile Durkheim (e.g. Luhmann, 1982: part 1). And both his major books - namely Soziale Systeme (1984) and Die Gesellschaft der Gesellschaft (1997) - are explicitly presented as a critical evaluation and modification of the work of Talcott Parsons, that is, 'the only systematic sociological theory that currently exists' (1997: 21). In this sense, his work can also be perceived as a reflection on the discipline's heritage, and as a contribution to classical discussions in sociology (see Vanderstraeten, 2001b). ${ }^{1}$

In this paper, I want to focus on one foundational aspect of Luhmann's theory of social systems, namely the theorem of double contingency. Luhmann's analyses of double contingency take their starting-point from some classical questions. How do two individuals who come face-to-face bridge the gap between them and establish a relation to one another? How does the other-orientation in each of the participants emerge and evolve in a social relation? How is action coordination between ego and alter possible? In Luhmann's systems theory, the theorem of double contingency is introduced at a basic level to analyze the emergence of social systems. But, as is well known, Talcott Parsons was the first to name and give precise formulation to this theorem. Parsons already regarded 'double contingency' as a theoretical concept that is necessary to account for the possibility of social interaction and, by extension, of social order. Luhmann's analyses are a systematic reconsideration of Parsons' treatment of 'the fundamental proposition of the double contingency of interaction' (Parsons, 1968: 436). In order to explore Luhmann's interpretations, it is therefore necessary to start with a discussion of Parsons' formulation of this fundamental theorem.

Talcott Parsons (1902-79) introduced the concept of double contingency in 1951 in the almost simultaneously appearing Toward a General Theory of Action, an anthology edited with Edward Shils, and The Social System. ${ }^{2}$ His concept differentiates two aspects. On the one hand, double contingency draws attention to the potential hazard of conflict between individuals confronting each 
other face-to-face; on the other hand, it points toward accomplishments that could lead to cooperation and sharing. The doubly contingent situation is an unavoidable basic condition that generates a problem at the social level that requires a solution if social interaction and social order are to be possible. Parsons takes the view that the norms and values of a 'shared symbolic system' solve the basic problem of double contingency. In his theoretical framework, he made a normative orientation - with the assumption of consensus - an indispensable feature of any system of interaction (see Parsons, 1951: 36ff.; 1973). As I will attempt to demonstrate, however, it is important to make the move from the problem of double contingency to ideas about its solution with care. It is also at this point that Luhmann's and Parsons' interpretations diverge.

In the introductory 'General Statement' of Toward a General Theory of Action, Parsons et al. start their account of double contingency by distinguishing

. . between objects which interact with the acting subject and those objects which do not. These interacting objects are themselves actors or egos. . . . They will be referred to as social objects or alters. A potential food-object ... . is not an alter, because it does not respond to ego's expectations and because it has no expectations of ego's action; another person, a mother or a friend, would be an alter to ego.

(1951: 14-15)

If another actor is treated as an interacting object, as an alter or alter ego, this changes the picture in important regards. When one focuses on the interaction of ego and alter, the analysis has to shift from the orientation of a single given actor to the consideration of two or more interacting actors as a system. Parsons et al. formulate their point of view as follows: 'It is the fact that expectations operate on both sides of the relation between a given actor and the object of his orientation which distinguishes social interaction from orientation to nonsocial objects' (1951: 15). Ego does not expect the behavior of a nonsocial object to be influenced by expectations regarding his/her own behavior, although ego's behavior is influenced by his/her expectations concerning the behavior of the nonsocial object. But the interaction of ego and alter is dependent on the integration of the mutual expectations of both actors. Social interaction is basically characterized by a 'complementarity of expectations' (Parsons et al., 1953: $35 \mathrm{ff}$.$) .$

Parsons' point of departure is that ego will only be motivated to engage in an interaction when ego can expect a constructive or gratifying reaction from alter in the interaction. Owing to personal 'need-dispositions' and gratification interests, ego's expectations will be oriented both to the range of alternatives for alter's actions, and to alter's selection within this range of alternatives. And because 
alter's reaction depends on what ego does, ego will have to interpret the meaning of his/her own actions for alter.

In interaction ego and alter are each objects of orientation for the other. The basic differences from orientations to nonsocial objects are two. First, since the outcome of ego's action (e.g. success in the attainment of a goal) is contingent on alter's reaction to what ego does, ego becomes oriented not only to alter's probable overt behavior but also to what ego interprets to be alter's expectations relative to ego's behavior, since ego expects that alter's expectations will influence alter's behavior. Second, in an integrated system, this orientation to the expectations of the other is reciprocal or complementary.

(Parsons and Shils, 1951: 105)

In other words, ego needs to expect the expectations of alter concerning ego's behavior. The obverse is true for alter. The expectations and actions of each of the participants become oriented to the expectations and actions of the other.

The concept of 'double contingency' was introduced to define this basic structure, and to distinguish interaction from other forms of action, such as the instrumental manipulation of physical or biological objects. In the aforementioned 'General Statement' of Toward a General Theory of Action, Parsons et al. employ the following formulation:

There is a double contingency inherent in interaction. On the one hand, ego's gratifications are contingent on his selection among available alternatives. But in turn, alter's reaction will be contingent on ego's selection and will result from a complementary selection on alter's part.

In The Social System, Parsons (1951: 94) likewise identifies two 'contingency factors' that result in double contingency, namely the contingency of what an actor actually does in the context of an elementary interaction situation and the contingency of the other's reaction to what is being done. In interaction, one might furthermore add, the determination of goals and actions transcends the purely individual or subjective level. It becomes dependent on the interaction process in which ego and alter participate. The ensuing, emergent order can then be called a social system.

In later publications, Parsons has occasionally returned to this topic. In a contribution to the International Encyclopedia of the Social Sciences, entitled 'Social Interaction', he states 'the fundamental proposition' of the double contingency of social interaction in the following words:

The crucial reference points for analyzing interaction are two: (1) that each actor is both acting agent and object of orientation both to himself and 
to the others; and (2) that, as acting agent, he orients to himself and to others and, as object, has meaning to himself and to others, in all of the primary modes or aspects. The actor is knower and object of cognition, utilizer of instrumental means and himself a means, emotionally attached to others and an object of attachment, evaluator and object of evaluation, interpreter of symbols and himself a symbol.

(1968: 436)

Strictly speaking, this elaborate formulation identifies a condition of double 'double contingency'. There is double contingency for ego and for alter in situations of social interaction. Parsons employs this formulation, on the one hand, to distinguish once more between the action of isolated actors and the interaction of two or more actors, and, on the other hand, to point to the integration of the autonomy of ego and alter in a social system. The social system of interaction itself also acquires autonomy. It becomes a reality sui generis because of the condition of double contingency (1968: 437; see also Parsons, 1951: 24ff.).

The analysis of the internal structure of interaction reveals an immanent circularity: Alter's behavior depends on ego's, and/while ego's behavior depends on alter's. As Parsons points out clearly, this is not a problem of mere behavioral agreement, or of coordinating the interests and intentions of different actors. It concerns a basic condition of possibility for social action as such - for action cannot take place if alter makes his action dependent on how ego acts, and ego wants to connect his action to alter's. In other words, the immanent circularity of the condition of double contingency makes action indeterminable. One can then raise questions such as: How do two actors who encounter each other in a situation of interaction relate to one another? How are ego and alter able to expect each other's expectations? What allows the two actors to make a selection from among available alternatives? How is interaction between ego and alter possible? Parsons' classical solution for the problem of double contingency takes the form of cultural determination. He argues that the long-term structures that regenerate social order lie in a cultural inheritance, and thus in the past. Already available cultural value patterns penetrate action orientations to such an extent that the existence of a value consensus can be assumed in interaction situations. But is this the only solution that is possible?

Let us first take a closer look on Parsons' way of solving and eliminating the problem of double contingency. In Toward a General Theory of Social Action, Parsons and Shils focus their analysis on the neo-Kantian, transcendental question of the minimal conditions of social stability. What is required to account for the existence of social order? The starting-point of their analysis is that ego and alter can only anticipate each other's future expectations and actions when the alternatives open to alter 'have some measure of stability in two respects: first, as realistic possibilities for alter, and second, in their meaning to ego' (1951: 105). 
From the perspective of ego's 'need-dispositions' and gratification interests, alter's action alternatives must have more or less the same meaning in a range of situations. The kind of meaning stability that Parsons has in mind presupposes generalization from the particularity of the given situations of ego and alter. It presupposes that action acquires a symbolic function that transcends the particular situations of interaction. 'When such generalization occurs, and actions, gestures, or symbols have more or less the same meaning for both ego and alter, we may speak of a common culture existing between them, through which their interaction is mediated' (1951: 105). Thus conceived, culture functions as a medium that can be employed by ego and alter in different social contexts.

Parsons also emphasizes that this common cultural or symbolic system cannot merely be understood as a medium for the transmission of information. If ego wants to be understood by alter, if ego wants to elicit constructive reactions, ego will have to respect the conventions that regulate the use of symbols. This type of solution for the 'problem of order' implies a normative orientation of the behavior of the participants.

It will then be a condition of the stabilization of such a system of complementary expectations, not only that ego and alter should communicate, but that they should react appropriately to each other's action. A tendency toward consistent appropriateness of reaction is also a tendency toward conformity with a normative patterns. The culture is not only a set of symbols of communication but a set of norms for action.

(Parsons and Shils, 1951: 106)

And in the article 'Social Interaction', Parsons chooses the following formulation:

The most important single condition of the integration of an interaction system is a shared basis of normative order. Because it must operate to control the disruptive potentialities (for the system of reference) of the autonomy of units . . . such a basis of order must be normative. It must guide action by establishing some distinctions between desirable and undesirable lines of action which can serve to stabilize interaction.

(1968: 437)

This concept of a shared basis of normative order is, in Parsons' view, 'basically the same as that of a common culture' (1968: 437).

Parsons' position can be reconstructed as follows. When ego begins to adopt an elementary orientation toward alter in an indeterminate interaction situation, then ego engages in signification or symbolization. This means that ego is bringing into play an expectation that necessarily involves abstraction or generalization from the particularities of the situation. When alter now reacts to 
ego in contingency on ego's proposal, alter also articulates an expectation and thus engages in a further step of symbolization that reinforces the structuring effect of the first symbolization step. Parsons argues that two actors (who have already acquired a symbolic system) act and react in particular ways in a specific situation such that they thereby activate relatively stable and more or less shared cultural forms that give the situation a sufficiently abstract or generalized meaning to make communication possible. At present, it can readily be seen that this position and this type of solution for the problem of double contingency are based on a past-oriented, objectivist and reified concept of culture (see Habermas, 1987: 204ff.; 1996: 139ff.; Strydom, 2001: 167ff.). The constitution of social systems is bound to cultural forms that are always already on hand - but how can the emergence and function of these forms themselves then be explained? Moreover, the problem of social order becomes a problem of education, for interaction is thought to depend on the correspondence between the expectations and normative orientations ego and alter have acquired through socialization and education. But which concept of socialization is then employed (see Vanderstraeten, 2000)?

Even in his later works, Parsons continued to underline the regulative role of culture and the importance of 'socialization to the grounds of consensus' (1966: 14).

The maintenance of a normative order requires that it be implemented in a variety of respects: there must be very considerable - even if often quite incomplete - compliance with the behavioral expectations established by the values and norms. The most basic condition of such compliance is the internalization of a society's values and norms by its members, for such socialization underlies the consensual basis of a societal community.

(1966: 14)

A discussion of the implications of this 'oversocialized view of man' would divert us from the argument of this article (Parsons, 1962; Wrong, 1961). The point that needs to be stressed here is that Parsons employs a negative conception of double contingency. He identifies double contingency with the nonsocial, the nonadapted. Parsons stresses the importance of values and norms, because this symbolic order is able to regenerate social order and to eliminate the basic problem of double contingency (see also Parsons \& Bales, 1956: 195). However, one might ask whether the basic problem in the constitution of interaction really lies in eliminating what is harmful or cannot adapt. In Luhmann's words: 'Is it enough to conceive social order as a boycotting of boycotting, or must one not know from the beginning how it is generally possible and sufficiently probable?' (1995a: 116). As Luhmann indicates, the problem that Parsons bequeaths to contemporary social theory is in the first place the problem of a 'postmodern' account of the basic condition of social interaction. 
The concept of double contingency is especially prominently positioned in Luhmann's book Soziale Systeme (1984), which became available in English in 1995 under the title Social Systems. ${ }^{3}$ The third chapter of this book is entirely devoted to a discussion of the concept. It forms the nexus between Luhmann's reflections on a general theory of systems and his detailed presentation of the armamentarium of a theory of social systems. 'The concept that is the theme of this chapter leads directly into the theory of social systems' (1995a: 103). Building on the foundations laid by Parsons, Luhmann discusses double contingency as a problem that motivates the constitution of social systems. He acknowledges that a completely indeterminate situation (i.e. 'pure' double contingency) never occurs in our societal reality. It can only be conceived as a kind of conceptual 'limit'. But, in contrast to Parsons, Luhmann is interested in the potential positive aspects of double contingency. He argues that the condition of double contingency cannot be neutralized or eliminated if social interaction is conceived as the confrontation of at least two autonomous systems (ego and alter). It is a problem that is constantly regenerated in social interaction, and thus imbues social systems with a basic instability (see Baecker, 2001: 66ff.; Blom, 1997: 112ff.; Vanderstraeten, 2002).

Luhmann's reformulation of the theorem of double contingency is first of all based on a broader definition of the concept of contingency. In Parsons' work, 'contingent' is predominantly used in the sense of 'dependent on . . ' The double contingent character of social interaction refers to the mutual dependency of ego's and alter's expectations and actions. Thus defined, it is indeed obvious to see the solution for the problem in forms of mutual restraint, of conformity to basic rules, and of the internalization of common cultural values. In contrast with this perspective, Luhmann returns to the original interpretation of contingency in modal theory (Aristotle).

Contingency means that being depends on selection which, in turn, implies the possibility of not being and the being of other possibilities. A fact is contingent when seen as selection from other possibilities which remain in some sense possibilities despite a selection.

(Luhmann, 1976: 509)

The concept describes 'something given (something experienced, expected, remembered, fantasized) in the light of its possibly being otherwise; it describes objects within the horizon of possible variations' (Luhmann, 1995a: 106). ${ }^{4}$ This means that ego's action is not contingent while it depends on another actor, but while it presupposes a selection from a range of alternative options. The double contingent character of social interaction is, mutatis mutandis, a consequence not of the mutual dependency of ego and alter, but of the confrontation of at least two autonomous systems that make their own selections in relation to one another. Luhmann (1981: 14) makes clear that dependency can be a consequence 
of this confrontation of ego and alter, but that dependency can also exactly be avoided in this confrontation.

This more abstract and broader theoretical reformulation rules out approaches that try to solve the problem of double contingency (even when it does not call it that) with concepts like reflection, symmetry, reciprocity or complementarity of perspectives. The unity being sought cannot merely be seen as a kind of 'stapling together' of what is different. That way, one would underestimate the complexity of the relationship of ego and alter, and the emerging 'eigen-selectivity' of this social system. Luhmann's critique is especially directed against the work of George H. Mead - notwithstanding Parsons' positive discussion of Mead as a classic author on this topic (Parsons, 1968: 434-5). Symbolic interactionism builds a contingently acting alter into ego and sees, quite correctly, the process of mediation as the use of symbols. But it treats the problem only on one side of the interaction, assuming that all is the same on the other. It treats, so to speak, only half of the double contingency. It confines itself to ego's actions, reflections, expectations and anticipations. Social systems emerge 'through (and only through) the fact that both partners experience double contingency and that the indeterminability of such a situation for both partners in any activity that then takes place possesses significance for the formation of structures' (Luhmann, 1995a: 108). This new unity cannot be grasped via the concept of action - as Mead, Parsons and others use it - because a constitutive feature of action is that it must be attributable to individuals. It can only be grasped via the concept of communication.

Luhmann argues that the complexity of social systems rules out the participants' reciprocally fully understanding each other; it rules out understanding every variant of system performance that each one individually contemplates. The participants are opaque and incalculable to one another. Hence, one can also talk of ego and alter as black boxes. 'The basic situation of double contingency is then simple: two black boxes, by whatever accident, come to have dealings with one another' (1995a: 109). These black boxes cannot really understand each other, but they can create sufficient transparency or 'whiteness' for dealing with one another.

For the few aspects through which they deal with one another, their capacity for processing information can suffice. They remain separate; they do not merge. . . They concentrate on what they can observe as input and output in the other as a system in an environment. . . They can try to influence what they observe by their own action and can learn further from the feedback. In this way an emergent order can arise that is conditioned by the complexity of the systems that make it possible but that does not depend on this complexity's being calculated or controlled.

(1995a: 110; see also 1990: 52ff.) 
Or, as Ranulph Glanville (1982) aptly entitled his study on the foundations of cybernetics: 'Inside every white box there are two black boxes trying to get out.'

Luhmann underlines that if an ego experiences an alter as alter ego and acts in this experiential context, his/her action becomes almost automatically an action 'for you', 'against you' or 'in front of you'. This means that ego's action controls itself from the perspective of the alter ego. This ego/alter ego constellation forms the nucleus of social interaction. To what extent the individual black boxes 'really' play a part in the interaction is another question. It is now well known that interaction allows for various forms of 'presentation of self' (Goffman, 1959; see also Kieserling, 1999). In a more or less similar way, Luhmann (1995b: 142ff.; 1997: 642ff.) maintains that there exist various forms and degrees of 'personalization' of social systems. This notion expresses the dependence of the social system on the personal attributions of the participants. It indicates not only that the degree of reciprocal knowledge required to reproduce the social system varies with the type of social system, but also that social systems themselves create the transparency sufficient for reciprocal observation and communication. One can think, for example, of the different forms of personalization in family relationships (love, education), on the one hand, and during shopping in supermarkets or fast-food restaurants, on the other. These examples also indicate that what is possible and necessary in interaction systems depends on the variety of types that emerge in the course of sociocultural evolution (see Vanderstraeten, 2001a).

Let us now consider in a more systematic way the implications of Luhmann's reformulation of the problem of double contingency for his conceptualization of its solution. If everyone acts contingently and thus everyone could also act differently and knows this about him- or herself and others and takes it into account, it is, for the moment, improbable that one's own action will generally find points of connection (and with them a conferral of meaning) in the actions of others. The circularity of the relationship brings about indeterminacy; self-commitment would presuppose that others commit themselves and vice versa. 'As long as ego cannot act without knowing how alter will act and vice versa, the system is underdetermined and thereby blocked.' But, so Luhmann adds, 'for meaning systems this means at the same time becoming highly sensitive to almost any determination' (1995a: 131). In a sense, the problem thus incorporates its own solution. In contrast to Parsons, Luhmann believes that this solution is not dependent on the existence of social consensus. The solution relies first of all on the temporal aspects of social interaction.

Beginning is easy. Strangers begin by reciprocally signalling each other indications of the most important behavioral foundations: the definition of the situation, social status, intentions. This initiates a system history that includes as well as reconstructs the problem of contingency. As a result, 
the system increasingly is occupied with arguments about a self-created reality: with handling facts and expectations that the system itself has helped to create.

(1995a: 131-2)

After the first steps, double contingency is no longer given in its original, circular indeterminacy. Every new step still appears as 'being also otherwise possible' - but only against the background of what has already been determined.

Luhmann does not resort to ab extra solutions for the problem of double contingency in interaction. He argues that the appearance of the problem comes to initiate a process of solving it; this solution is not founded in human nature, or regulated by cultural values that have prior validity.

What the experience of contingency achieves is the constitution and opening up of chance for conditioning functions within the system, thus, the transformation of chance into structural probabilities. Everything else is a question of selecting what proves its worth and what has further usefulness.

(1995a: 120)

In this line of reasoning, the experience of double contingency creates a sensitivity to chance. Everything that happens in such a situation, every action, every gesture, every expression, appears as a relevant, meaningful selection. After the first gesture, every subsequent step becomes an action with a contingencyreducing effect - be it positive or negative. The initial situation constitutes a takeoff situation. The open or pure, undetermined version of double contingency ego will do what alter wants if alter does what ego wants - is supplemented by a structured version that takes into account determinations and alternatives, and that gets constituted in the process of interaction. 'The system emerges, etsi non daretur Deus [even if God doesn't exist]' (1995a: 105).

This point of view implies that social interaction constantly reproduces its own double contingent character. Following Luhmann, social systems use double contingency as stimulus for the restructuring or reconditioning of their own processes. He speaks of 'auto-catalysis' in social systems. 'Thus the problem of double contingency has the properties of an autocatalytic factor: without itself being "consumed", it enables the construction of structures on a new level of ordering, which is regulated by that perspective on perspectives. Thereby - and this is why one can speak of "auto"-catalysis - the problem of double contingency is itself a component of the system that it forms' (1995a: 120). The experience of contingency gives rise to the formation of a social system, but this experience depends itself on the generation of meaningful issues in the social system. Seen in this light, research about the very origins of social order looses its relevance. 'Persons never meet without some assumption, without some expectations about 
each other, and they can experience contingency in the sense of "always being otherwise possible" only by means of behavioral types and expectations' (1995a: 133). It can now also be understood why Luhmann chooses to emphasize the positive role of double contingency. His elaborations are first of all intended to enable the development of an armamentarium for the analysis of social phenomena such as instability, dissent, change, and evolution. One might also say that his elaborations try to deconstruct the usual notion of system - and to do away with any presumptions of hierarchical control, order, or predictability (Luhmann, 1997: 36ff; see Baecker, 2001). In this sense, I have previously spoken of a 'postmodern' account of social order.

For Luhmann, double contingency is a pre-eminent social problem. The solution of this problem requires the use of a pre-eminent social operation, namely communication. Social order can only be produced by means of communication, although/while it is this order that also enables communication. Luhmann's social systems theory incorporates self-reference; his communication theory is explicitly concerned with the exploration of this self-referential constitution of social order (e.g. Luhmann, 1982: 59-63). In this regard, one can once more see that Luhmann's account of double contingency sharply diverges from Talcott Parsons' account. For Parsons, social order eventually has a nonsocial origin. Ego and alter apparently solve the problem of double contingency not by communication, but by introspection. One way or another, each of the participants comes to recognize the necessity of shared norms and values. The foundations of social order are located in individual willingness and individual reason, even if socialization plays a crucial role for the 'social animal' (Luhmann, 1981: 13-16). For Luhmann, however, the condition of double contingency initiates communication, and this communication inevitably constitutes a social system as a network of meaningful reciprocal selections - which reproduces the very problem of double contingency.

Against this background, it can be seen that the condition of double contingency enforces the differentiation of social systems and human beings. Social systems are emergent realities that use communication to process meaning. They consist of communications, not of human beings (the term indicates both the psychic and the organic systems of human beings). Human beings are part of the social environment, and vice versa. But the differentiation of social and psychic systems is not equal to mutual isolation. Communications can be at the same time conscious events; thoughts can be communicated. These systems can converge or 'interpenetrate' in individual elements, because they are radically temporalized systems. Their elements are continually replaced by other elements or 'events' (different thoughts, different communications). 'They give each of them a different selectivity and connectivity, different pasts and futures. . . The elements signify different things in the participating systems, although they are identical as elements: they select among different possibilities and lead to different consequences' (Luhmann, 1995a: 215). For human beings, the so-called 'turn- 
taking' of active and passive participation in communication almost inevitably re-establishes the difference between psychic and social systems. The mind might, for example, wander, think of something incommunicable, interrupt or pause, while the burden of communicating passes to somebody else. On the other hand, psychic systems do not have to accept what is communicated, or how it is communicated. They can reject the communicative events (Vanderstraeten, 2000). In this sense, Luhmann clearly provides us with an account of social systems as a reality sui generis.

Finally, it should be noted that Luhmann's elaborations are directed against the moralistic schemes of observation that dominate in the field of the social sciences. With Talcott Parsons and other 'critical theorists' of the New World in mind, Luhmann made a number of cynical remarks in Die Gesellschaft der Gesellschaft:

To an astonishing degree and more than all others, American sociology has positioned itself to stand up for the Good and to accept the Bad, at best, as a form of 'deviance' that should be the target of social reform efforts. It perfectly copies the classic story of American movies: the Good has a terrible time, it almost fails against its adversaries; but in the end it triumphs against all odds, drives off in a shiny new car and gets a wellearned kiss.

Sociology has established itself as a 'science of crises' - and, as a consequence, has become trapped in its own theory crisis (1997: 1132). Its research agenda has become second to the adopted moral agenda. Instead of trying to offer a moralistic scheme to the rest of the world, sociology should concentrate on the deconstruction of common, self-evident perspectives. From Luhmann's perspective, social systems theory looks at communicating and observing in society; and from here it gradually reconstructs how time directs our doings and how we risk our presentations of self in interaction with others.

In this article, I have indicated that double contingency is always regenerated during the process of social interaction. Strictly speaking, the problem of double contingency is a problem that cannot be solved. Luhmann's elegant solution is possible because his analysis takes as its point of departure the autonomy of social systems. Only complex psychic systems (i.e. black boxes) in the environment of the social system are able to regenerate the experience of contingency. Because 'the theory deals with a free-floating reality, a selfgrounding enterprise' (1995a: 123), social order can only be created in the social world itself. It is on the basis of this presumption that Luhmann tried to provide a theoretical framework for the analysis of the fundamental features common to all social systems. 


\section{Notes}

The author acknowledges funding by the European Commission (HPMF-CT-2000-00835).

1. In a discussion of Émile Durkheim's The Division of Labor in Society, Luhmann has proposed the following understanding of classical texts in sociology:

The text retains its contemporary relevance so long as its way of posing problems can still be accepted. However, it remains an authoritative standard in an ambivalent sense: from it we can infer what must be achieved, but no longer how it is to be achieved.

(1982: 4)

A text is classical if it furnishes a set of claims that is no longer convincing in its original form, but that survives as a challenge, desideratum or problem. While its formulation of a particular problem survives, its solution for that problem is no longer acceptable. It is also in this sense, by drawing a distinction between problem and solution, that I discuss the theorem of double contingency.

2. Perhaps it is not redundant to point here to the fact that Toward a General Theory of Action sought to introduce the development of general theory in the social sciences (sociology, psychology and cultural anthropology). The book was a joint product of several outstanding researchers: Talcott Parsons, Edward A. Shils, Edward C. Tolman, Gordon W. Allport, Clyde Kluckhohn, Henry A. Murray, Robert R. Sears, Richard C. Sheldon and Samuel A. Stouffer. They all contributed to the book's introductory 'General Statement'.

3. This 675-page work was conceived as 'the introductory chapter' of his theory of society. In a number of other monographs, this general theory of social systems has been applied to function systems of our contemporary society (economy, science, law, art, religion, politics and education). Luhmann's chef d'oeuvre is the 1200-page book Die Gesellschaft der Gesellschaft (1997), which appeared one year before his death. Here, Luhmann presented the final chapter of his theory of society.

4. An action is also defined by the set of possibilities from which it is selected. That is why Luhmann, with reference to phenomenology (Edmund Husserl), also speaks of the 'horizon' of possible references made expectable by every action.

\section{References}

Baecker, Dirk (2001) 'Why Systems?', Theory, Culture, \& Society 18(1): 59-74. Blom, Tannelie (1997) Complexiteit en Contingentie. Kampen: Kok Agora.

Glanville, Ranulph (1982) 'Inside Every White Box There Are Two Black Boxes Trying To Get Out', Behavioral Science 27: 1-11.

Goffman, Erving (1959) The Presentation of Self in Everyday Life. New York: Doubleday.

Habermas, Jürgen (1987) The Theory of Communicative Action, Vol. 2. Boston: Beacon.

Habermas, Jürgen (1996) Between Facts and Norms. Cambridge, MA: MIT Press.

Kieserling, André (1999) Kommunikation unter Anwesenden. Frankfurt am Main: Suhrkamp. 
Luhmann, Niklas (1976) 'Generalized Media and the Problem of Contingency', pp. 507-32 in Jan J. Loubser, Rainer C. Baum, Andrew Effrat and Victor M. Lidz (eds) Explorations in General Theory in Social Science: Essays in Honor of Talcott Parsons. New York: Free Press.

Luhmann, Niklas (1981) Soziologische Aufklärung 3. Opladen: Westdeutscher Verlag.

Luhmann, Niklas (1982) The Differentiation of Society. New York: Columbia University Press.

Luhmann, Niklas (1984) Soziale Systeme. Frankfurt am Main: Suhrkamp.

Luhmann, Niklas (1990) Soziologische Aufklärung 5. Opladen: Westdeutscher Verlag.

Luhmann, Niklas (1995a) Social Systems. Stanford: Stanford University Press.

Luhmann, Niklas (1995b) Soziologische Aufklärung 6. Opladen: Westdeutscher Verlag.

Luhmann, Niklas (1997) Die Gesellschaft der Gesellschaft. Frankfurt am Main: Suhrkamp.

Parsons, Talcott (1951) The Social System. Glencoe, IL: Free Press.

Parsons, Talcott (1962) 'Comment on "The Oversocialized Conception of Man" by Dennis Wrong', Psychoanalysis and Psychoanalytic Review 10(2): 322-34.

Parsons, Talcott (1966) Societies. Englewood Cliffs, NJ: Prentice Hall.

Parsons, Talcott (1968) 'Social interaction', pp. 429-40 in David L. Sills (ed.) International Encyclopedia of the Social Sciences, Vol. 12. New York: Macmillan/Free Press.

Parsons, Talcott (1973) 'Culture and the Social System Revisited', pp. 33-46 in Louis Schneider and Charles M. Bonjean (eds) The Idea of Culture in the Social Sciences. Cambridge: Cambridge University Press.

Parsons, Talcott and Robert F. Bales (1956) Family, Socialization and the Interaction Process. London: Routledge \& Kegan Paul.

Parsons, Talcott and Edward A. Shils (1951) 'Categories of the Orientation and Organization of Action', pp. 53-109 in Talcott Parsons and Edward A. Shils (eds) Toward a General Theory of Action. Cambridge, MA: Harvard University Press.

Parsons, Talcott, Edward A. Shils, Gordon W. Allport, Clyde Kluckhohn, Henry A. Murray, Robert R. Sears, Richard C. Sheldon, Samuel A. Stouffer and Edward C. Tolman (1951) 'Some Fundamental Categories of the Theory of Action: A General Statement', pp. 3-29 in Talcott Parsons and Edward A. Shils (eds) Toward a General Theory of Action. Cambridge, MA: Harvard University Press.

Parsons, Talcott, Robert F. Bales and Edward A. Shils (1953) Working Papers in the Theory of Action. New York: Free Press.

Strydom, Piet (2001) 'The Problem of Triple Contingency in Habermas', Sociological Theory 19(2): 165-86. 
Vanderstraeten, Raf (2000) 'Autopoiesis and Socialization. On Luhmann's Reconceptualization of Communication and Socialization', British Journal of Sociology 51(3): 581-98.

Vanderstraeten, Raf (2001a) 'The School Class as an Interaction Order', British Journal of Sociology of Education 22(2): 267-77.

Vanderstraeten, Raf (200lb) 'Observing Systems: A Cybernetic Perspective on System/Environment Relations', Journal for the Theory of Social Behaviour 31(3): 297-311.

Vanderstraeten, Raf (2002) 'The Autopoiesis of Educational Organizations. The Impact of the Organizational Setting on Educational Interaction', Systems Research of Behavioral Science 19(3): 243-53.

Wrong, Dennis (1961) 'The Oversocialized Conception of Man in Modern Sociology', American Sociological Review 26(2): 183-93.

Raf Vanderstraeten is a Senior Researcher at the University of Bielefeld, Germany. He has held appointments at the University of Leuven (Belgium) and at Utrecht University (the Netherlands). His research interest is in social systems theory and sociology of education.

Address: Fakultät für Soziologie, Universität Bielefeld, PO Box 1001 31, 33501 Bielefeld, Germany. [email: Raf.Vanderstraeten@uni-bielefeld.de] 